\title{
NUMERICAL ANALYSIS OF SLAB WITH DIFFERENT SHAPES OF OPENINGS
}

\section{PRITPAL KAUR, INDERPREET KAUR \& MANAV GUPTA}

Guru Nanak Dev Engineering College, Ludhiana, Punjab, India

\begin{abstract}
Slabs are the concrete elements used as significant components in building. It is common to have openings in slabs for various structural reasons like electrical, mechanical and plumbing services as a result decreases their capacity to carry loads. Along with this, insufficient data is available for slabs having openings at centre and at eccentric positions to resist applied loads. Moreover, many difficulties were faced analytically while modelling the complex behaviour of RCC slabs in nonlinear zone. Therefore they require special attention in both analysis and design. This research gives more attention on studying structural behaviour of two way slab having openings at centre and at eccentric positions along with solid slab. To study this type of behaviour seven different models of square slabs having different shapes of openings like square, rectangular and circular at centre and eccentrically has been generated in ANSYS, which is a FEM based software. All specimens were subjected to load, which was increased from zero to failure load. The effects of opening shape on crack formation were also analysed.
\end{abstract}

KEYWORDS: ANSYS, Slab, Opening, Deflection, Crack Pattern

Received: Mar 30, 2019; Accepted: Apr 19, 2019; Published: May 20, 2019; Paper Id.: IJCSEITRJUN20198

\section{INTRODUCTION}

Undeniably slabs as a part of structures plays very vital role in transferring load normal to their plane. Mostly concrete slabs are used as floors in different buildings like industrial, residential and so on. Along solid slabs, slabs with small as well as large openings are also required for fulfilling the purpose of plumbing, for providing pipes for fire protection, ducts for heat, ventilation and air conditioning, on the other hand big openings has been required for stairs and shafts for elevators which ultimately reduces the maximum load carrying capacity of slabs because of cutting of both concrete and reinforcing steel(Seliem, Sumner, Seracino, \& Smith, 2008).Because these openings are generally provided near columns, the quantity of concrete available near columns is reduced (Liberati, Marques, Leonel, Almeida, \& Trautwein, 2019) which cause reduction in the punching shear capacity of the slab connection and increase the likelihood of punching failure(Ismail, 2018).The location and sizes of openings as per requirement are predetermined in the early stages of design, for construction of new slabs and then accordingly it can be accommodated. Cutting openings in RC slabs is still a critical issue in spite of all the precautions \& it needs to be studied furthermore (Mahlis, Elkareim, Abd, \& Sherif, 2018).

The problems concerning with design of slab with openings is very complicated, therefore it cannot be solved by analytical method. While experimental based testing has been widely used for analysis to produce real life response of concrete strength under loading, it is extremely time consuming and the use of materials can be quite costly(Srinivasan \& Sathiya, 2010).On the other hand, in the present scenario, it become possible to analyse complicated structures like slab having openings by using powerful computers and advanced software's which make it possible to create accurate results by following Finite Element Method. Nowadays many recent software's 
are available in the market, of which the results obtained from commercial software package ANSYS has showed a good agreement with experimental results (Kachlakev, Miller, Yim Chansawat, \& Potisuk, 2001). In this research ANSYS has been used to model various slab models having openings and solid slab without any opening to understand their behaviour by providing various types of openings at centre and at eccentric positions. The main focus of this study is to determine the effect of different shapes of openings at different positions on its stress region and deflection resistance.

\section{MATERIAL AND METHODOLOGY}

In the present work, ANSYS which is powerful engineering software and is based on finite element method is used for investigation of numerical analysis of different slab models. This software has been generated by following recent technology which ultimately helps in solving problems related to linear as well as nonlinear simulations. In this study, the dimensions of the solid slab was considered as 450x450x40(mm) and various slab openings used in solid slab are given in Table 1.

Table 1: Descriptions of Openings Used in Slab

\begin{tabular}{|c|c|l|}
\hline S.No. & Slab Symbol & \multicolumn{1}{c|}{ Description } \\
\hline 1 & S1 & Solid Slab \\
\hline 2 & S2 & Slab with square opening $(75 \times 75 \mathrm{~mm})$ at an eccentricity of $75 \mathrm{~mm}$ from center of the slab. \\
\hline 3 & S3 & Slab with rectangular opening $(75 \times 150 \mathrm{~mm})$ at eccentricity of $75 \mathrm{~mm}$ from center of the slab \\
\hline 4 & S4 & Slab with circular opening $($ diameter $75 \mathrm{~mm})$ at eccentricity of $75 \mathrm{~mm}$ from center of the slab \\
\hline 5 & S5 & Slab with square opening $(75 \times 75 \mathrm{~mm})$ at center of the slab. \\
\hline 6 & S6 & Slab with rectangular opening $(75 \times 150 \mathrm{~mm})$ at center of the slab. \\
\hline 7 & S7 & Slab with circular opening $($ diameter $75 \mathrm{~mm})$ at center of the slab. \\
\hline
\end{tabular}

\section{Modelling of Concrete}

The different models of concrete slabs has been created by using solid 65 element present in ANSYS software, which has eight nodes and each node has three degrees of freedoms in $\mathrm{x}, \mathrm{y}$ and $\mathrm{z}$ directions. In three orthogonal directions plastic deformation, cracking and crushing is possible by selecting solid 65 element. A schematic diagram of this element is shown in Figure 1.

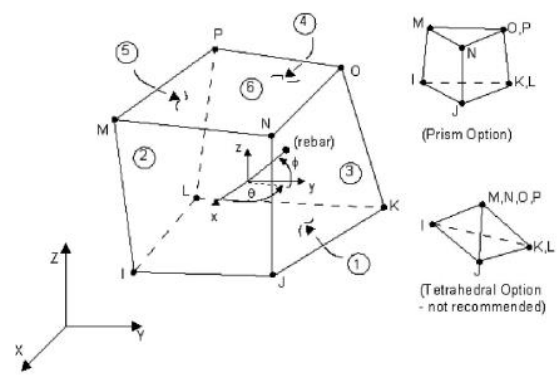

Figure 1: Solid 65 Element

Table 2: Properties of Concrete Prior to Initial Yield Surface

\begin{tabular}{|l|l|c|c|}
\hline Material & Material Model & $\begin{array}{c}\text { Modulus of Elasticity } \\
\left(\mathbf{k N} / \mathbf{m}^{\mathbf{2}}\right)\end{array}$ & Poisons Ratio \\
\hline Concrete & Linear elastic & $2.236 \mathrm{e} 7$ & 0.12 \\
\hline
\end{tabular}


Table 3: Parameters of Concrete beyond Initial Yield Surface

\begin{tabular}{|l|c|}
\hline Open shear transfer coefficient & 0.4 \\
\hline Closed shear transfer coefficient & 1 \\
\hline Uniaxial cracking stress & 1.98 \\
\hline Uniaxial crushing stress & -1 \\
\hline
\end{tabular}

\section{Modelling of Steel Reinforcement}

For providing reinforcement in slab models Link 8 element has been used which has a 3D spar element and has two nodes which further has three degrees of freedom inn $\mathrm{x}, \mathrm{y}$ and $\mathrm{z}$ directions along with capability of plastic deformation. The diagram of this element is shown in Figure 2.

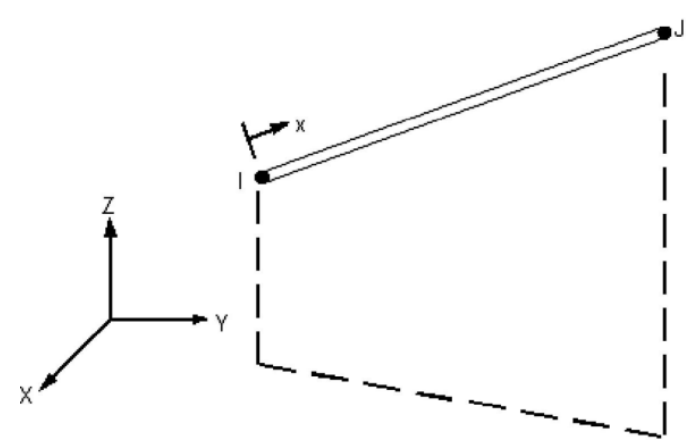

Figure 2: Link 180-3-D Spar

Table 4: Properties of Reinforcement within Link 180 Element

\begin{tabular}{|l|l|c|c|}
\hline Material & Material model & Modulus of Elasticity & Poisons Ratio \\
\hline Structural Steel & Linear elastic & $2 \mathrm{e} 8$ & 0.3 \\
\hline
\end{tabular}

Table 5: Parameters of Concrete Beyond Initial Yield Surface

\section{MESHING}

\begin{tabular}{|c|l|}
\hline Yield strength & $\mathbf{4 1 5} \mathbf{M p a}$ \\
\hline Tangent Modulus & 0 \\
\hline
\end{tabular}

The slab models were meshed in square and rectangular elements as this options are avail in solid65 element. For meshing the slabs volume mapped command was used. The meshing was done by giving the appropriate element divisions, which further helps in assigning proper length and width of appropriate divisions.

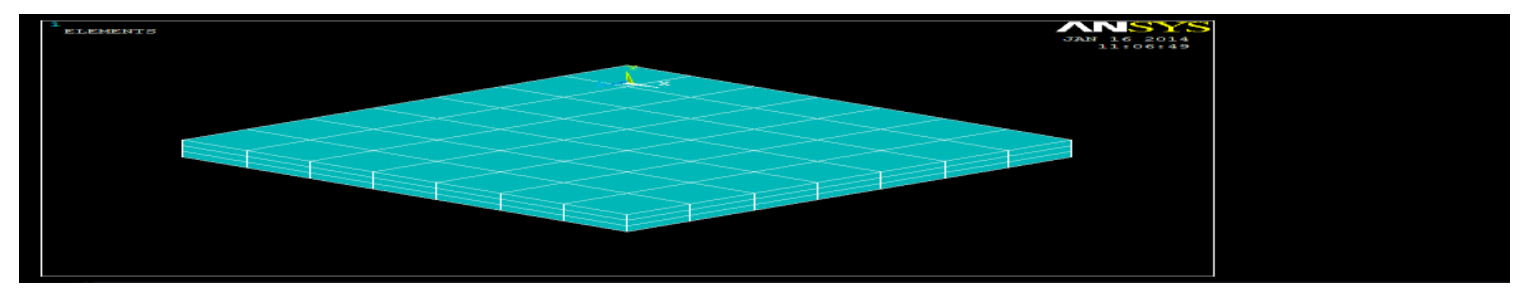

Figure 3: Model showing Meshing of Solid Slab 


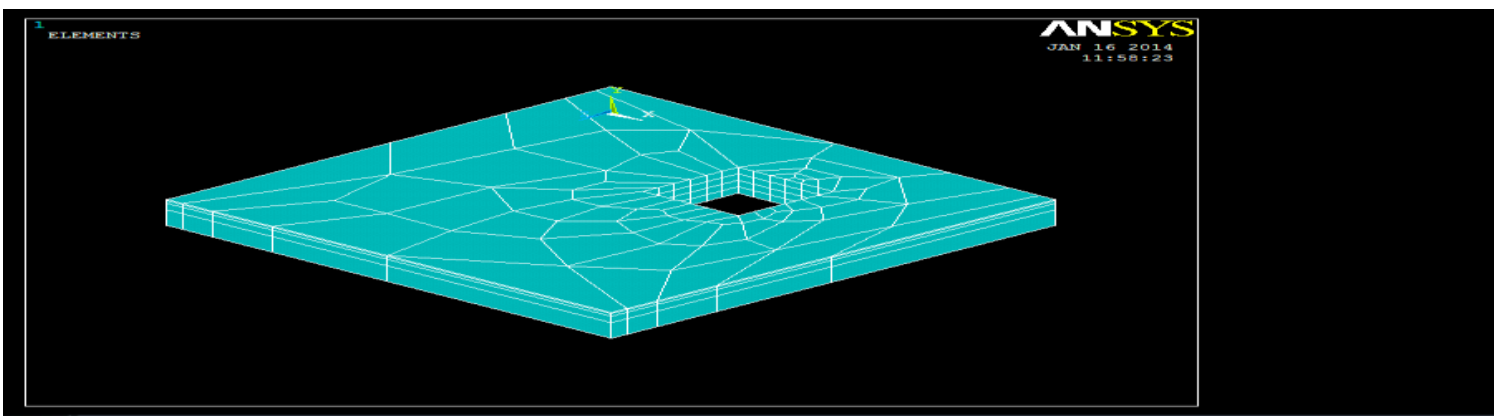

Figure 4: Model Showing Meshing of Slab with Eccentric Square Opening

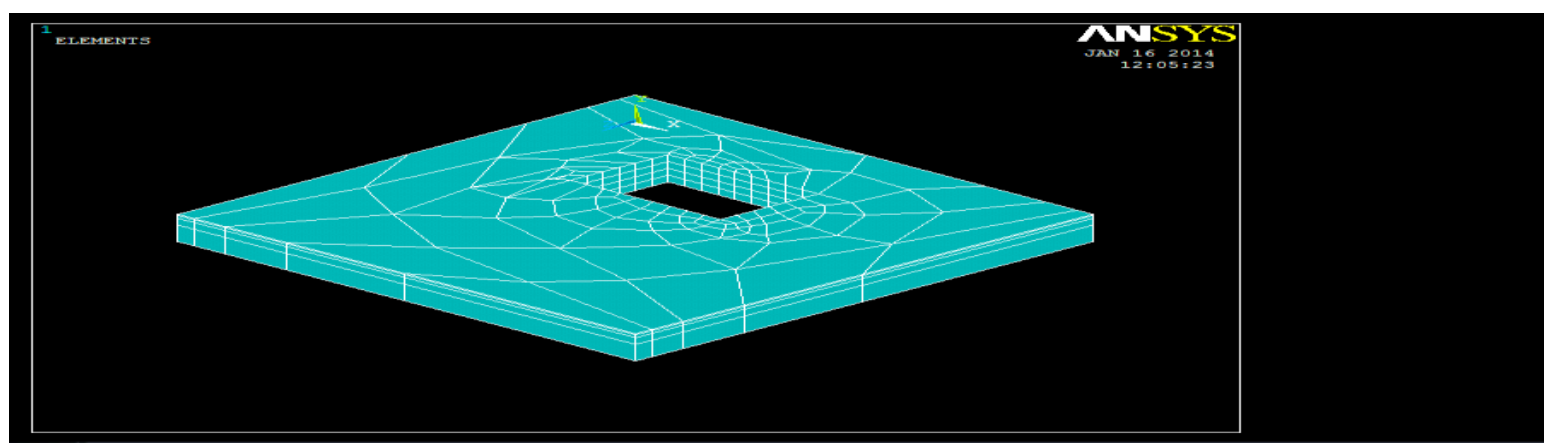

Figure 5: Model showing Meshing of slab with Eccentric Rectangular Opening

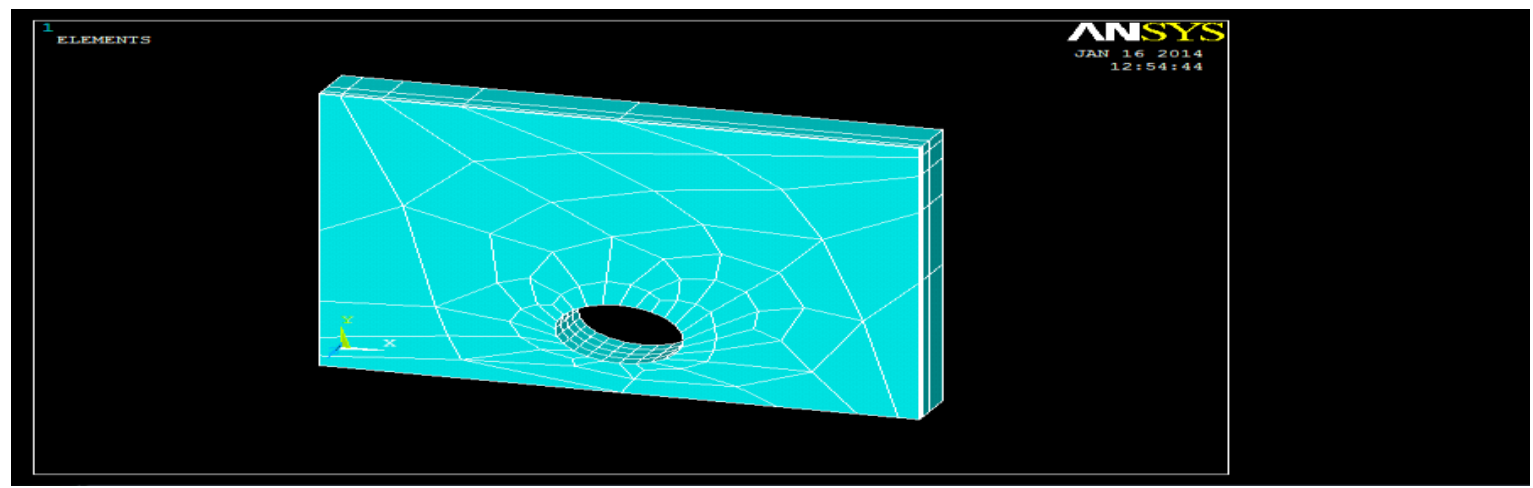

Figure 6: Model showing Meshing of Slab with Eccentric Circular Opening

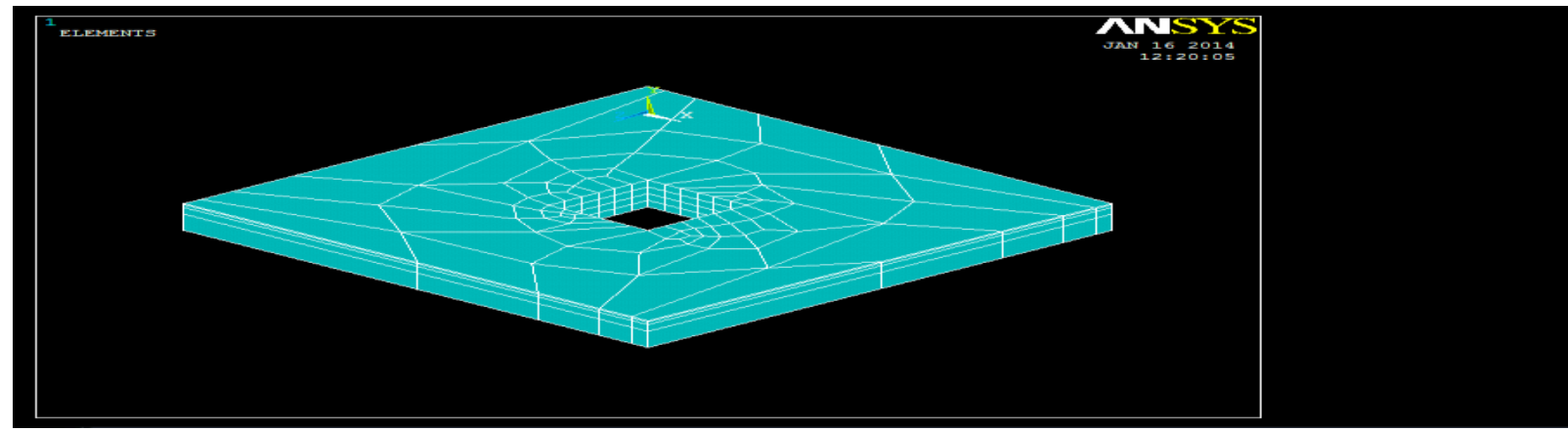

Figure 7: Model showing Meshing of slab with Square Opening at Centre 


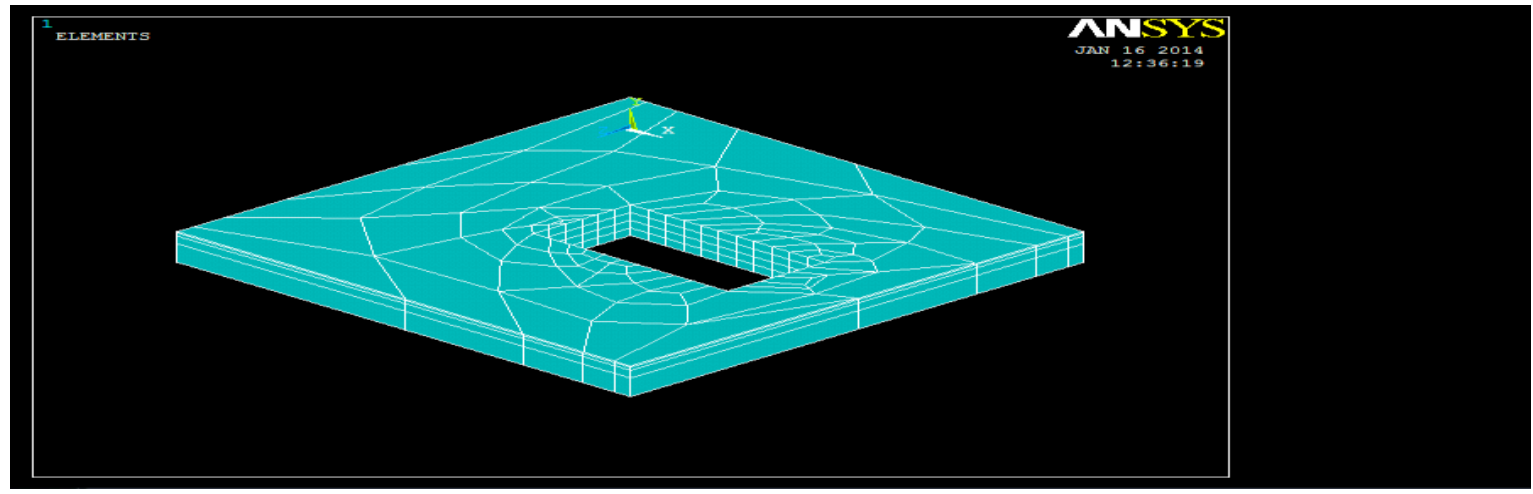

Figure 8: Model showing Meshing of slab with Rectangular Opening at Centre

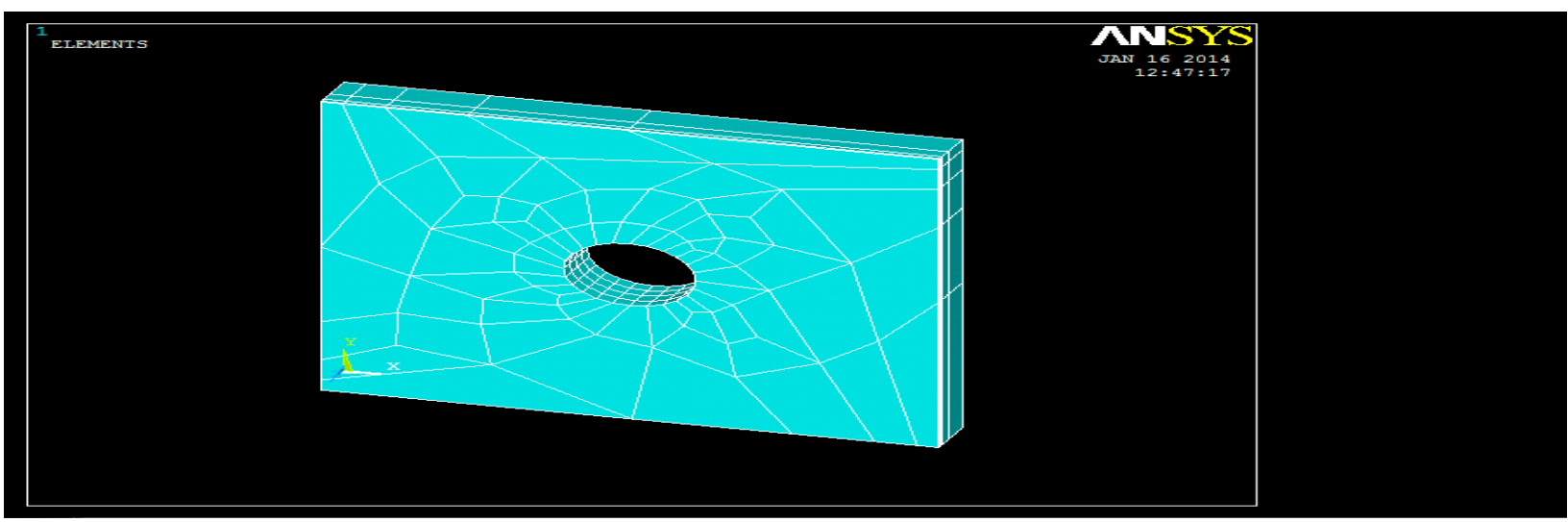

Figure 9: Model showing Meshing of slab with Circular Opening at Centre

\section{RESULTS AND DISCUSSION}

In the present work, slab without opening and with opening of rectangular, circular and square openings at different positions are being analysed and studied. The variation in deflection due to different openings in slab at centre and at eccentricity for different loads was compared with load deflection variation of solid slab is graphically shown in graph 1,2 and 3. From the graph it is clear that deflection is more in case of slab with opening and load carried by slab with opening is less as compared to solid slab. Along with this it has been analysed that slabs having eccentric openings carry more load as compared to slabs having openings at centre.

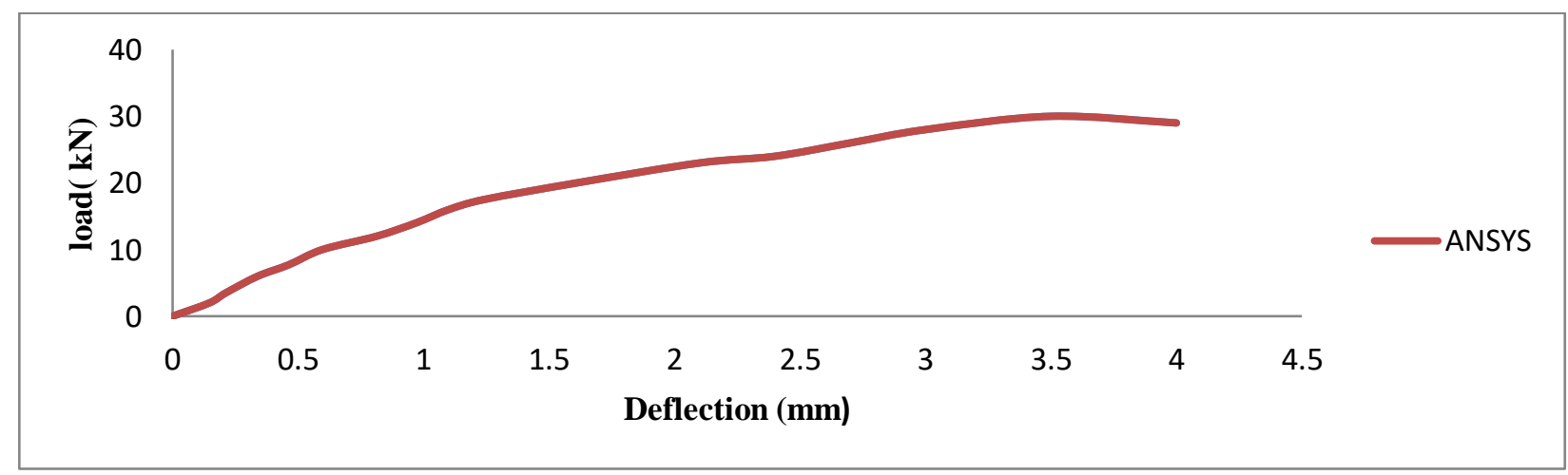

Graph 1: Load Deflection Curve of Solid Slab 


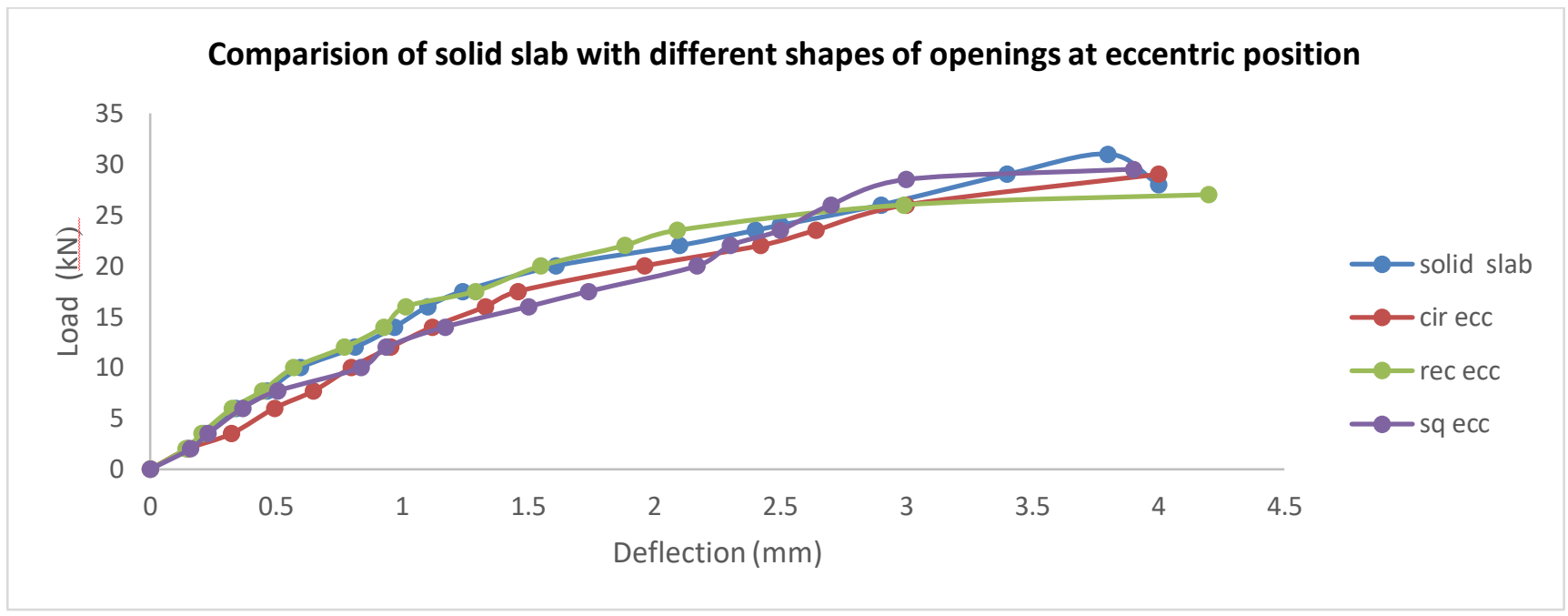

Graph 2: Load Deflection Curve of Solid Slab and Openings at Eccentricity Positions

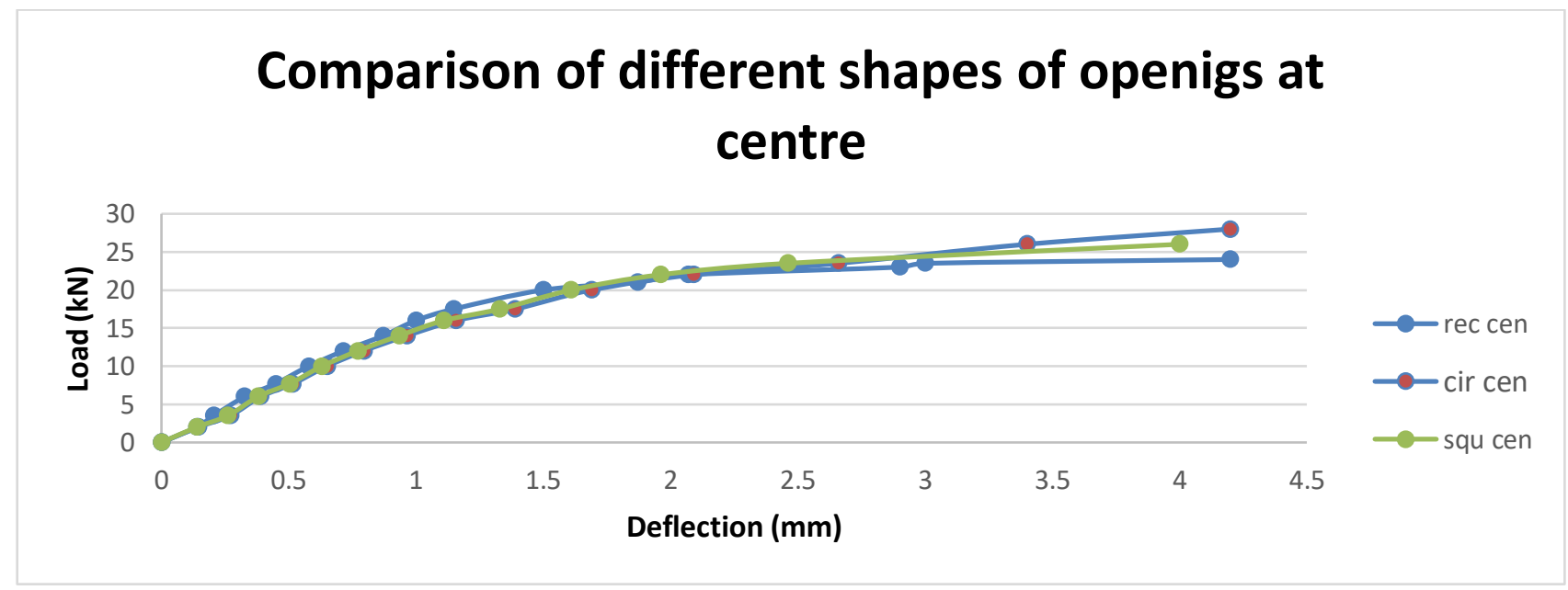

Graph 3: Load Deflection Graph of Different Shapes of Openings at Centre

\section{CRACK PATTERN}

Concrete is tension which causes cracking in tension side of the structures. Cracking starts at the surface and then penetrates inward. In all cases, most of the cracks occur near the opening as shown in figures below.

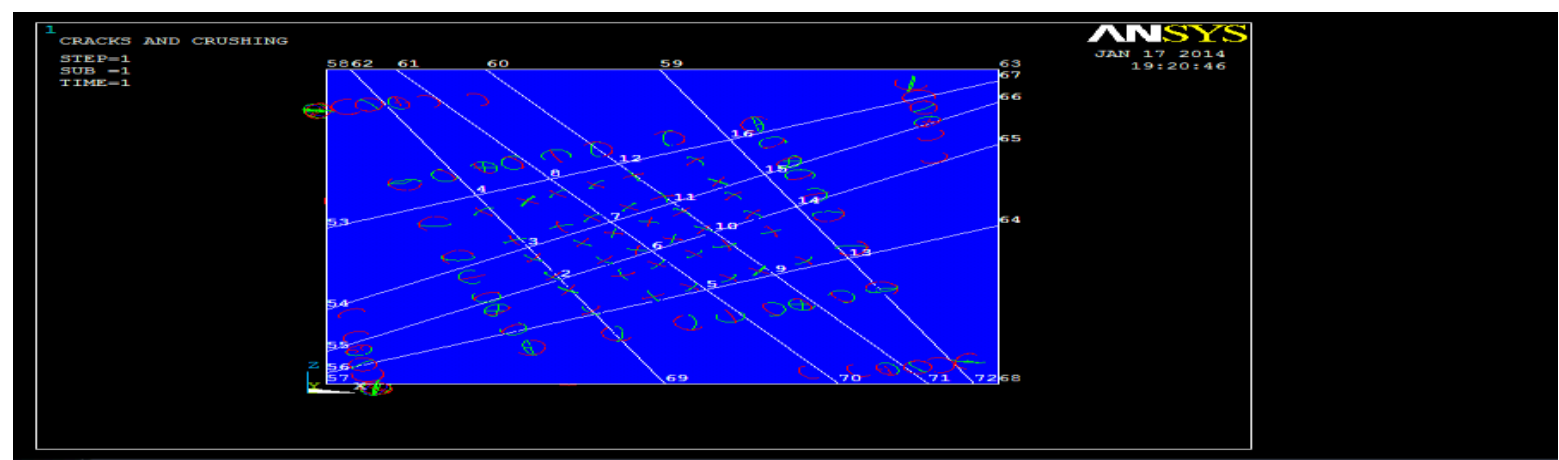

Figure 10: Crack Pattern of Solid Slab at Maximum Load. 


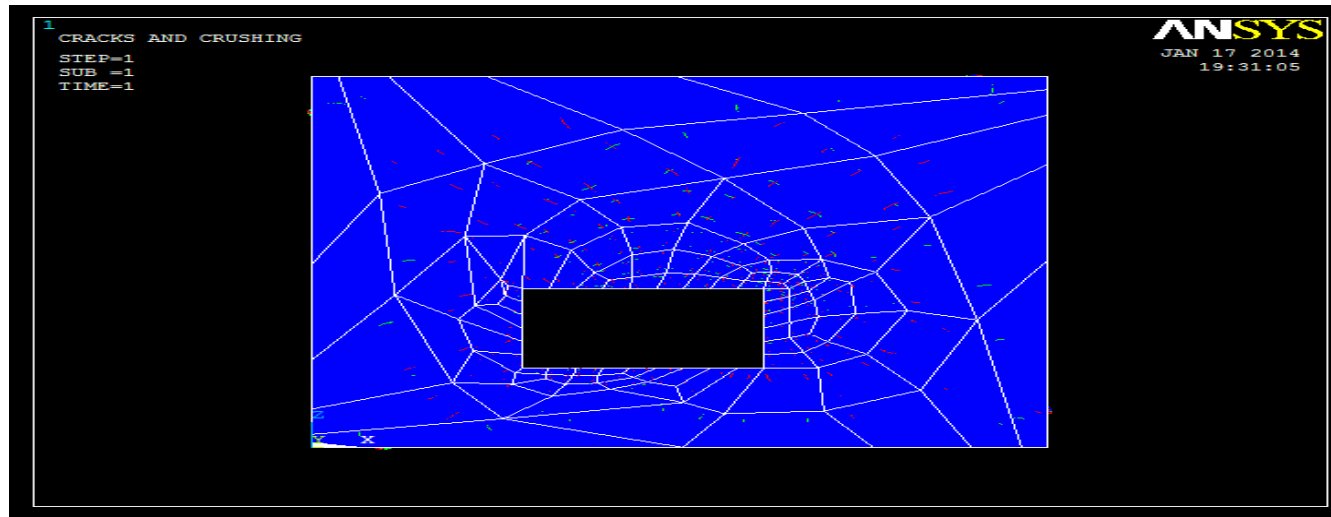

Figure 11: Crack Pattern of Slab Having Rectangular Opening at Eccentricity

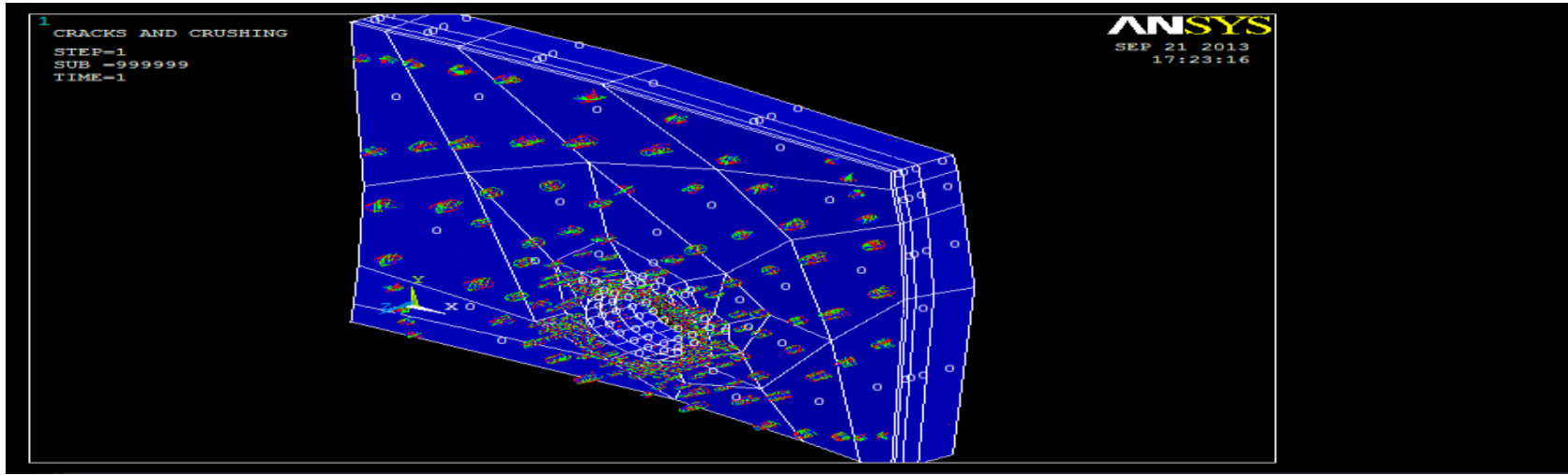

Figure 12: Crack Pattern of Slab Having Circular Opening at Eccentric Position

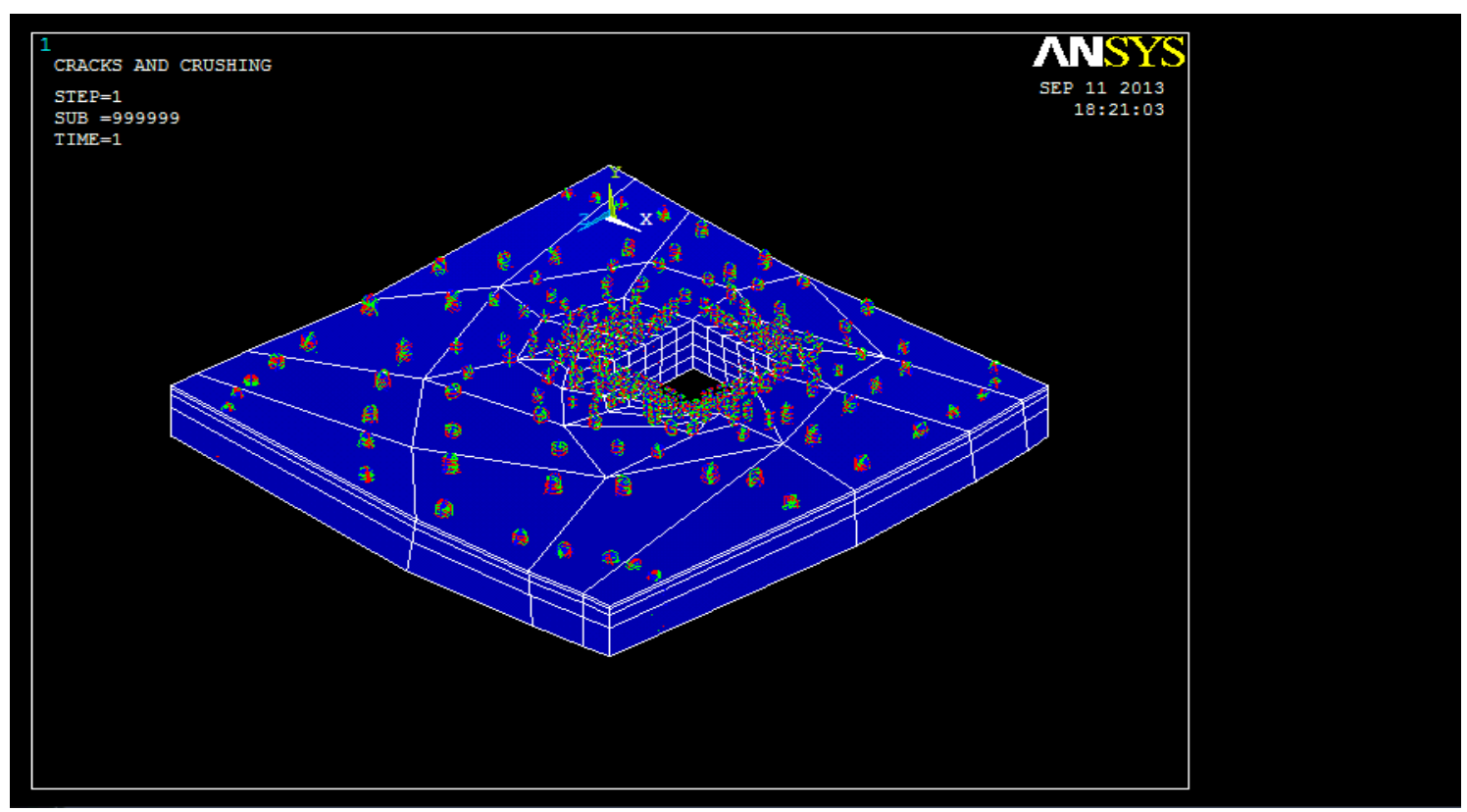

Figure 13: Crack Pattern of Slab Having Circular Opening at Eccentric Position 


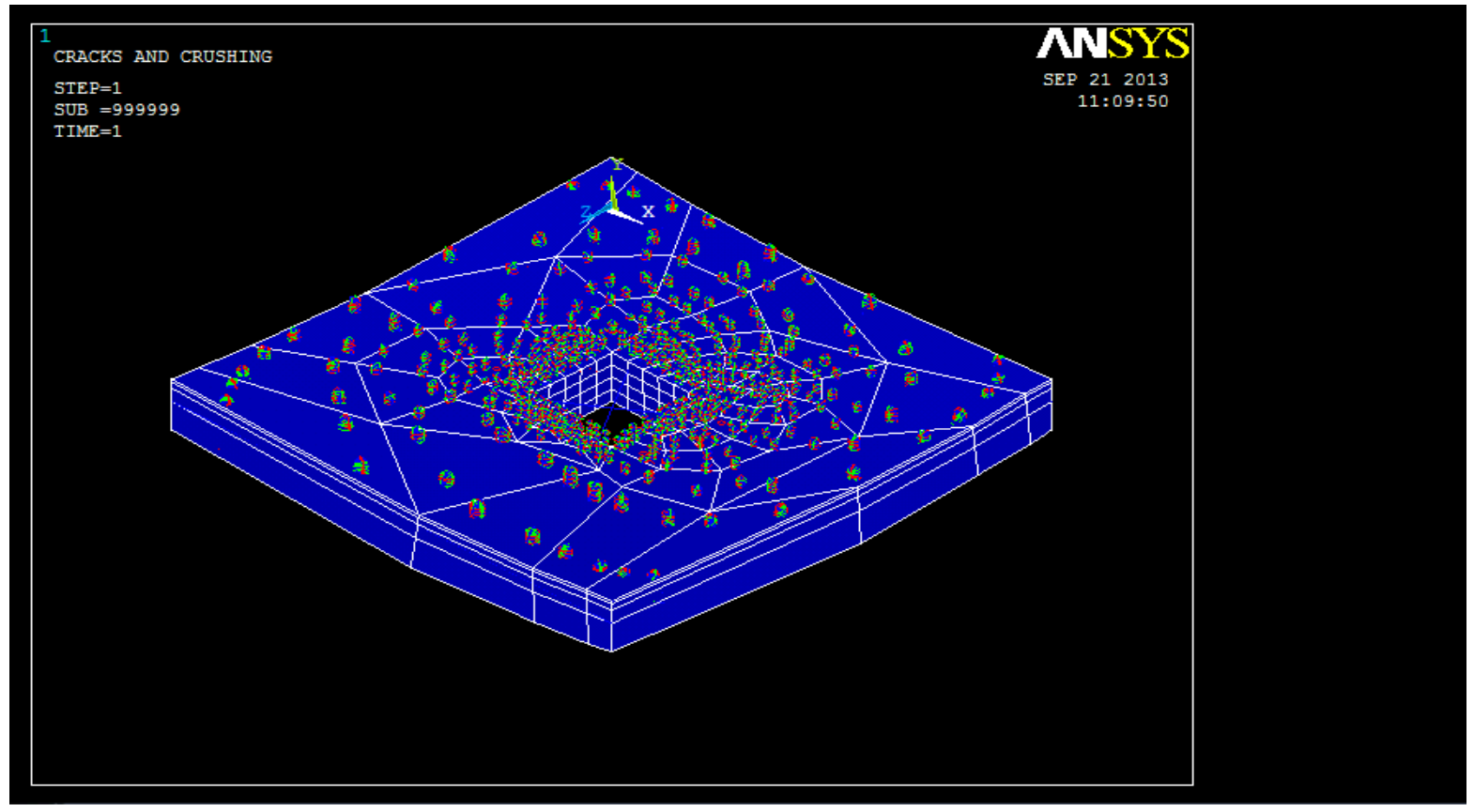

Figure 14: Crack Pattern of Slab having Circular Opening at Centre

\section{CONCLUSIONS}

It is observed from the results that:

- Ultimate load carrying capacity of slab having opening is less as compared to solid slab.

- Slab having circular opening shows better result to carry load than slabs having square and rectangular openings.

- Slab with rectangular opening carries less load and deflection as compared to square opening.

- The deflection of slab with eccentric opening is less than the slab having opening at center.

\section{REFERENCES}

1. R. Srinivasan and K. Sathiya (2010) Flexural Behaviour of Reinforced Concrete Beams Using Finite Element Analysis (ELASTIC ANALYSIS), Tomul LVI (LX), Fasc. 4.

2. Ismail, E. I. M. (2018). Non-linear finite element analysis of reinforced concrete flat plates with opening adjacent to column under eccentric punching loads. HBRC Journal, 14(3), 438-449.

3. Kachlakev, Miller, Yim Chansawat, \&, Potisuk, 2001.Finite Element Modeling ofreinforced concrete structures strengthened with FRP laminates

4. Liberati, E. A. P., Marques, M. G., Leonel, E. D., Almeida, L. C., \& Trautwein, L. M. (2019). Failure analysis of punching in reinforced concrete flat slabs with openings adjacent to the column. Engineering Structures, 182(November 2018), 331-343.

5. Mahlis, M., Elkareim, A., Abd, S., \& Sherif, A. (2018). The E ff ect of Cutting Openings on the Behavior of Two-way Solid Loaded Slabs ( a ) Specimen S1. Structures, 16(May), 137-149.

6. Seliem, H. M., Sumner, E. a, Seracino, R., \& Smith, S. T. (2008). Field testing of RC slabs with openings strengthened with CFRP. 22-24. 